IP Periodica Polytechnica

Transportation Engineering

44(4), pp. 193-200, 2016

DOI: $10.3311 /$ PPtr. 8870

Creative Commons Attribution (i)

RESEARCH ARTICLE

\section{Multi-Condition Contact Stress Analysis of High Speed Train Helical Gear}

\author{
Zhaoping Tang ${ }^{1 *}$, Shuai Tang ${ }^{1}$, Jianping Sun ${ }^{1}$, Li Yan ${ }^{2}$
}

Received 03 December 2015; accepted 03 March 2016

\begin{abstract}
Taking traction helical gear of CRH380A high speed train for example, not only analyzing the meshing process characters of the high speed train helical gear and the tractive performance curve, but also using Pro/E to complete a three-dimensional model, combining with ANSYS workbench, helical gear contact finite element model is built in start-up, continuous and high speed conditions. A meshing period equivalent stress and contact pressure distributions of gear tooth surface are obtained by solving the model. And so are the changing regularity of gear contact state and stress on the meshing process. The result shows that based on ANSYS workbench, dynamic contact stress analysis about traction helical gear of high speed train can reflect the realistic contact stress state among the meshing process. It provides some certain references and foundations to calculate the gear's strength analysis and modification design.
\end{abstract}

\section{Keywords}

traction helical gear of high speed train, finite element model, dynamic contact, stress analysis

\footnotetext{
${ }^{1}$ School of Information Engineering,

East China Jiao Tong University,

Nanchang Jiangxi, 330013, China

${ }^{2}$ CSR Qishuyan Locomotive \& Rolling Stock Technology

Research Institute Co. Ltd, Changzhou Jiangsu, 213011, China

"Corresponding author, e-mail: tzp@ecjtu.jx.cn
}

\section{Introduction}

Rail transit is evolving worldwide (Gašparík et al., 2015), and crucial in China. High speed transportation has become a symbol in Chinese modern railway. Traction helical gear as the critical component of high speed train for power supply plays a pivotal role in the process of train operation. In recent years, domestic and overseas have done much work about gear contact stress and finite element analysis model. Jabbour et al. (2015), Fedorko et al. (2016) put forward a method which can be used to calculate the distribution of the stress at the tooth root and of the contact stress along each contact line of helical gear. Conrado et al. (2011) applied the Dang-Van and the Liu-Zenner multiaxial fatigue criteria to judge the contact fatigue limit. And the relationship between the generated temperature and the contact fatigue limit was received. Wan et al. (2015) studied the effects about different helical gears parameters on mesh stiffness and the result shewed that the fluctuation degree of mesh stiffness decreases with the increasing helix angle or face width. Zong et al. (2014) researched the Chinese high speed train whose speed is more than 300 kilometers per hour, established time-varying model based on traditional classical dynamics and gear pair mesh stiffness, and realized dynamic simulation analysis to drive system when the high speed train was in start-up condition. Hu et al. (2011) and Ivenco et al. (2016) used explicit dynamic method with finite element software to explore the dynamic meshing characters in condition of the different modification coefficients and spiral angle parameters of helical gear pair. Patil et al. (2016) carried out the experimental testing and analysis of helical gear by using a newly designed test rig named Gear Dynamic Stress Test Rig. The experimental results provided an insight on how the actual strain and stress variations can occur. Wang et al. (2013) according to GB/T 3480-1997 and GB/T6413-2003 respectively examined bending fatigue strength, contact fatigue strength and scuffing load capacity, and then the bending, contact and scuffing safety factors about start-up, continuous and high speed conditions were respectively $2.82 \sim 4.78,1.54 \sim 2.18$ and $3.21 \sim 3.53$, demonstrating that the strength and scuffing load capacity were sufficient to the high reliability requirements of helical gear. The 
helical gear has the advantages such as smooth transmission, little noise and preferable meshing performance, so it is always adopted to achieve power transmission in high speed train. Simultaneously, when the traction helical gear of high speed train is in high speed operation, different forms of failures and damages such as tooth surface contact fatigue even tooth root bending fatigue and fracture may occur. All of these failures are related to the alternative contact and bending stresses when the gear is under the dynamic meshing process. In order to optimize the gear design, increase the working life of high speed train traction helical gear and improve the gear contact state, great significance is attached to the researching of gear contact stress and strain.

This paper comprehensively analyzed meshing characters of high speed train helical gear, studied tractive performance curve of CRH380A, and took the CRH380A train's G301 traction helical gear as an example, gear pair was established by Pro/e and then imported into ANSYS workbench to explore the nonlinear contact condition, mainly studied the dynamic contact stress state of helical gear during three working conditions as start-up, continuous and high speed. The contact pressure map and meshing characters of helical gear were obtained. The result showed that using ANSYS workbench can analyze the dynamic contact stress of helical gear. And the gear pair contact stress changing states about the different meshing positions can be acquired. As a result, it offers a theoretical basis for further study on structure optimization, modification design and fatigue strength of traction helical gear.

\section{Traction helical gear meshing characters analysis of high speed train}

High speed train is the train whose speed is more than 250 kilometers per hour. Gear meshing characters of high speed train are as follows: The traction gear of high speed train needs smooth transmission and always adopts helical gear whose contact ratio is large. The second is that the linear velocity of gear transmission is up to $50 \sim 70 \mathrm{~m} / \mathrm{s}$. On account of the centrifugal force effect with high linear velocity, the gear body will inflate in radial direction. This has a big influence on gear meshing contact process. The third is the heat, generated by high speed rolling-slip of tooth surface and the friction of high speed lubricant gas flow, makes the gear temperature distribution between the gear body and tooth width direction not balance. And the temperature difference of the gears will increase for the reason that the heat radiating area of small gear is smaller than the big one. The lubricant temperature of gear box will be more than $150^{\circ} \mathrm{C}$ when the train speed is higher than 350 kilometers per hour. The last one is that both gears adopt two sides support, so the bending and torsion deformations are relatively small. This improves the unbalance loading situation which always occurs when ordinary locomotive small gear employs cantilever structure.
CRH380 is the main high speed train in China. CSR Qingdao Sifang Company Limited realized the higher speed train whose test speed achieved 605 kilometers in Jan. 2014. This is a milestone for the development of Chinese high speed train (2015). The largest speed of CRH380A is 380kilometers per hour and continual running speed is about 350 kilometers per hour. So it has the fastest working speed and is the highest content of science and technology high speed train in currently China. In the meantime, the gear system of CRH380A has the drive and break functions, so the load applied on system is complexity. The traction helical gear G301 whose helical and normal pressure angles are respectively $20^{\circ}$ and $26^{\circ}$ is applied in CRH380A. Theoretically, when helical angle is bigger than $16^{\circ}$, axial force will be too large so that the temperature will rise rapidly. However, the normal pressure on tooth surface increases with the increasing pressure angle. Consequently, pitch line and meshing impact momentum will become larger than before. Particularly, when the gear transmission is at a high speed, the nonlinear impact and vibration noise which are caused by gear transmission error, gear body elastic and tooth thermal deformations will be magnified. Only through the precise modification design could the transmission requirements about high precision and high perfor- mance be satisfied.

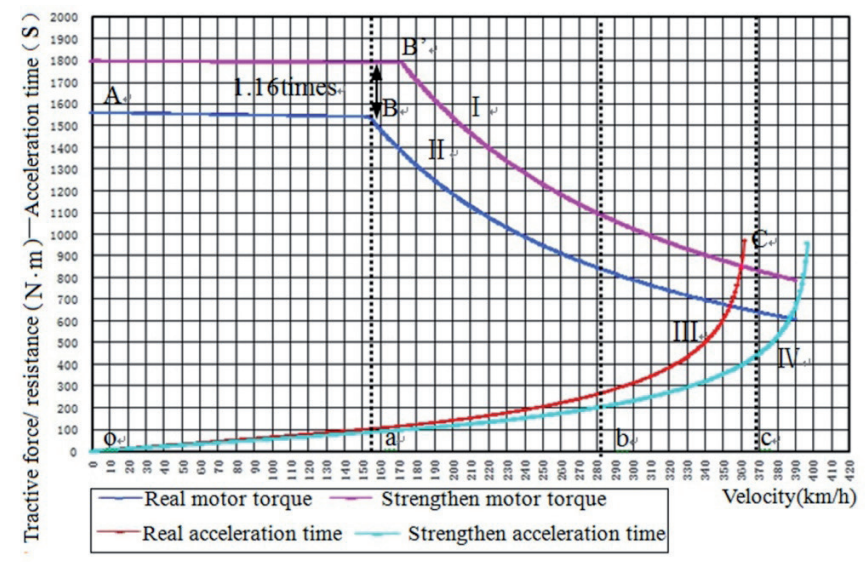

Fig. 1 Torque and acceleration time curves of traction motor onCRH380A high speed train-staff quota traction condition

The tractive performance curve, shown as Fig. 1, reflects the relationship among tractive effort, power and the running speed about the drive motor in the traction condition. Curve I and IV are respectively the designed curves of torque-time and acceleration-time. Curve II and III are respectively the actual curves of torque-time and acceleration-time. The straight part value of curve $\mathrm{I}$ is 1.16 times larger than point $\mathrm{B}$ on actual motor curve II . Moreover, flexing portion is also 1.1 to 1.2 times than actual motor curve II. Thereby, motor stable operation condition is satisfied. Oa portion is starting stage with constant torque of traction motor. Starting stage is a condition that locomotive from static state to normal operation. So starting stage is also named start-up condition. I and II curves show that the locomotive torque keeps 
a little big value in start-up condition and has a declined tendency with the increasing speed since the traction effort is subject to the starting current in this interval. Ab portion is continuous operation stage with constant power of traction motor. It is also named continuous condition which means that locomotive operates with the maximum constant power. The tractive effort is subject to the traction motor power in this interval. The operation of locomotive in this condition has a long time. At the same time, with the tractive effort decreasing, the acceleration and velocity will reduce and increase respectively. Bc portion is high speed stage of traction motor. It means that the locomotive operates at a certain high speed and is also named high-speed condition. The velocity of point $\mathrm{C}$ on curve III approaches 380 kilometers per hour and is the maximum speed point among the actual locomotive operation. In this condition, the revolving speed of the traction helical gear is a little high. The gear body inflates along with the radial direction, so the big meshing impact will be generated. Start-up, continuous and high speed conditions are the three main features in traction condition.

\section{Three-dimensional model establishment of gear pair}

G301 traction helical gear pair of CRH380A high speed train adopts high quality low carbon alloy steel 20CrNi2Mo. The small gear uses carbonize and quenching steel. And the tooth crest hardness is between 75 and $85 \mathrm{HS}$. The large gear uses high-frequency quenching steel, and the tooth crest hardness is between 65 and 75HS, tooth root hardness is larger than $60 \mathrm{HS}$. The main parameters of G301 traction helical gear are shown as Table 1. Compared with the ordinary high speed overloaded locomotive gear, the module is relatively small, but spiral and pressure angles are a little large.

Table 1 Basic parameters of G301 traction helical gear

\begin{tabular}{lccc}
\hline \multirow{2}{*}{ Name } & \multicolumn{3}{c}{ Gears } \\
\cline { 2 - 4 } & Small & Large \\
\hline Tooth number $z$ & 29 & 69 \\
\hline Module mn $/(\mathrm{mm})$ & & 26 & \\
\hline Pressure angle $\alpha /\left(^{\circ}\right)$ & & 20 & \\
\hline Helix angle $\beta /\left(^{\circ}\right)$ & 0 & & -0.284588 \\
\hline Modification coefficient & & 363 & \\
\hline Center distance $(\mathrm{mm})$ & & & \\
\hline
\end{tabular}

The gear's three-dimensional model can be acquired directly by Pro/E software and gear parameters. Besides, the model precision degree can satisfy requirements. Combined with center distance, the gear pair is assembled and is shown as Fig. 2.

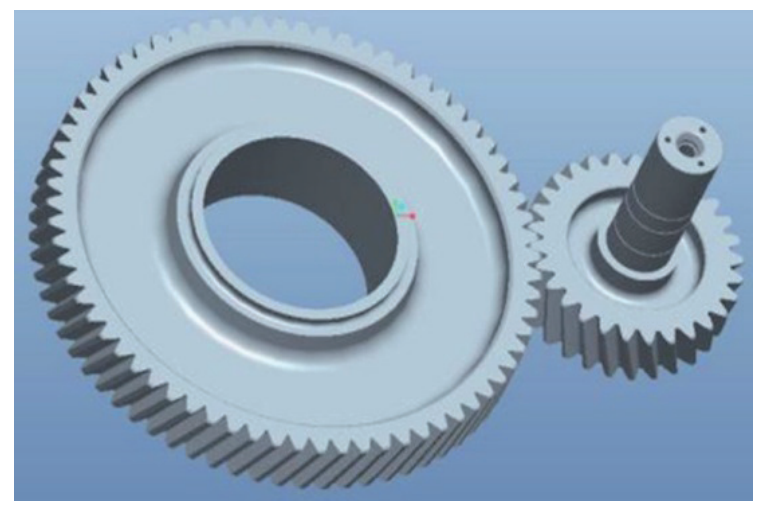

Fig. 2 Three-dimensional model of gear pair

\section{Dynamic contact finite element analysis of gear pair}

Transient dynamic analysis which belongs to time-domain analysis can explore the structure dynamic response process under the changeable time-load effect. The load changed with time is the input data, and the output data is the displacement which changes with time or other quantities such as strain and stress. Known from classical force theory, the common dynamic equation is as below.

$$
[M]\left\{x^{\prime \prime}\right\}+[C]\left\{x^{\prime}\right\}+[K]\{x\}=\{F(t)\}
$$

In formula (1), $[M]$ is mass matrix, $[C]$ is damping matrix, $[K]$ is stiffness matrix, $\{x\}$ is displacement vector, $\{F(t)\}$ is force vector, $\left\{x^{\prime}\right\}$ is velocity vector, $\left\{x^{\prime \prime}\right\}$ is acceleration vector.

Formula (1) can be seen as static equation which simultaneously considers damping force $[C]\left\{x^{\prime}\right\}$ and inertia force $[M]\left\{x^{\prime \prime}\right\}$ at any certain time $t$. For the equations at different times, the time increment $\Delta t$ between any adjacent times $t_{1}$ and $t_{2}$ is named integration time step. New-mark time integration method is used to solve the model in ANSYS workbench. In consideration of formula (1), this paper adopts full method to solve the transient dynamic analysis model, because the full method not only uses mass, damping and stiffness matrices to calculate the transient response of structure but also considers kinds of materials nonlinear characters containing creep, plasticity, large deformation and large strain (Tong et al., 2014).

\subsection{Three-dimensional grid model of gear pair}

When using ANSYS workbench to analyze helical gear contact stress, if the single tooth model is used, results like helical gear meshing basic status, contact deformation and stress cannot be denoted precisely. But if full tooth model is adopted, the elements quantity of finite element method will become oversize, therefore, the calculation time and efficiency of finite element method will be influenced. On the foundation of Saint Venant's Principle, this paper uses part of meshing gear model (Fan et al., 2010). The material attributes of small and large gears are defined as structural steel in ANSYS Workbench, the elastic modulus of big and small gears are respectively 
$2 \times 10^{11}$ and $2.06 \times 10^{11}$. Poisson's ratios are 0.29 and 0.3 . The tooth surface that has the possibility to contact should be grid refined at the same time. The model owns 323152 nodes and 189402elements totally shown as Fig. 3.

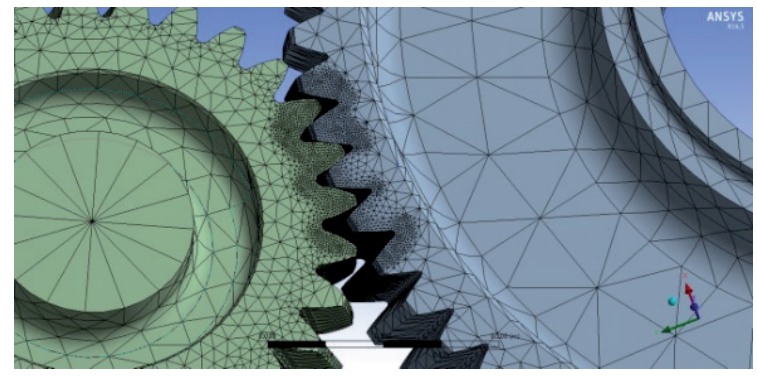

Fig. 3 Finite element model of gear contact part

\subsection{Contact pair establishment}

The gear pair contact belongs to face-to-face contact. In general case, small gear is more likely to be fatigue fracture compared with big gear. Thereby, the surface stiffness with small gear is larger than big gear at the manufacturing process. This paper, as a consequence, selects the target surface from small gear. In the physical sense, the contact bodies should not penetrate each other. Thereby, surface contact stiffness should be defined. For nonlinear entities surface contact, when the grid division meets precision requirement, contact penetration will decrease with the contact stiffness increasing. But, if the big contact stiffness is applied, the model solving process will not be convergent (Chen et al., 2011). In general case, contact stiffness value varies between 0.01 and 10 . In order to use appropriate contact stiffness value, the calculation should be done many times with the increasing contact stiffness until the contact stress has little change. The ideal contact stiffness coefficient of G301 helical gear in this paper is 0.03 and friction factor is 0.2 .

\subsection{The applied loads and constraints}

In the gear pair's working condition, both driving and driven gears have revolving speeds and torques. In the process of gear dynamic contact finite element analysis, when constraints are applied to gear pair, revolute joints are respectively added to driving and driven gears, the five freedom degrees of both driving and driven gears are restrained but a rotary motion is allowed. According to the actual work data, resisting torque should be applied to the revolute joint of driven gear, and revolving speed should be applied to the driving gear. There are big differences about the revolving speeds in different working conditions. So, in order to obtain the stress map of helical gear accurately at different locations, the calculation time step of helical gear under the three conditions should have some differences. Simultaneously, in order to ensure the calculation convergence, the revolving speed should increase linearly to corresponding value at some certain calculation time steps. Torques and revolving speeds of CRH380A traction helical gear in the three conditions containing start-up, continuous and high speed are displayed as Table 2. According to the corresponding references, the corresponding revolving speeds of driving gear in the three conditions are respectively 3.03, 2.60 and 1.93 times larger than the ordinary locomotive. And the torques are $0.199,0.114$ and 0.465 times in the corresponding condition. Apparently, compared with the ordinary locomotive, the traction helical gear transmission of high speed train has the features like low load and high speed.

Table 2 Torquesand revolving speeds of helical gear in the three conditions

\begin{tabular}{llll}
\hline & Start-up & Continuous & High speed \\
\hline $\begin{array}{l}\text { Torque } \\
(N \cdot \mathrm{m})\end{array}$ & 1900 & 841.5 & 569.5 \\
\hline $\begin{array}{l}\text { Revolving speed } \\
(\mathrm{rad} / \mathrm{s})\end{array}$ & 31 & 434 & 641 \\
\hline
\end{tabular}

\subsection{Calculation result analysis}

According to the actual working condition requirements, revolute joints are appended to the inner cylinder of the small and large gears. The torque in corresponding condition is added to the revolute joint of the big gear. And the revolute joint of the small gear is added by the revolving speed which increases linearly to corresponding value at some certain calculation time steps. New-mark time integration method and full method are used to solve the model. Equivalent stress and contact pressure maps about traction helical gear in the three conditions can be obtained. Taking the helical gear stress in startup condition for example, equivalent stress map of the meshing gears is extracted at a certain instant, so the displacement variations of helical gear can be obtained. As Figure 4 shows, the stress distribution of finite element model displays that the maximum equivalent stress of gear pair locates in contact area and diffuses to the gear body gradually. Meanwhile, the stress concentration also occurs in tooth root. The same method is used to analyze continuous and high speed traction conditions.

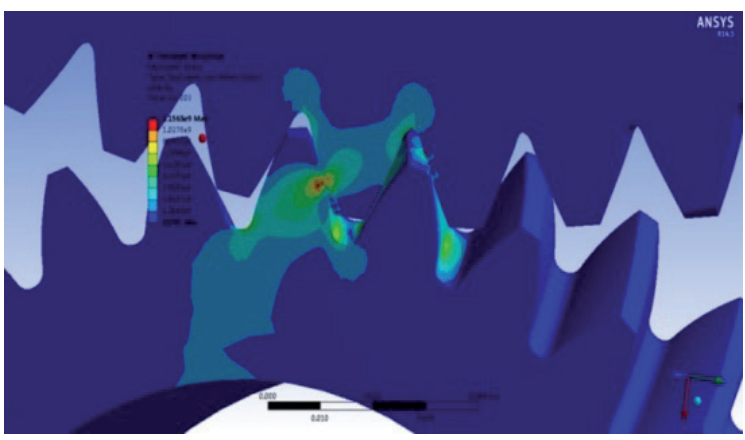

Fig. 4 Equivalent stress map of gear contact part in start-up condition

Contact pressure maps of gear pair in different meshing positions are extracted and displayed in Fig. 5, 6 and 7 in the three conditions. Figure (a), (c), (d) and (f) are contact pressure maps 
of gear pair in normal meshing positions. Figure (b) and (e) are respectively the contact pressure maps of mesh in and out. The figures indicate that both the location and dimension of the maximum contact pressure have certain variations at different instants in the same condition. In the start-up, continuous and high speed conditions, the maximum contact pressure of helical gear pair increases gradually with the promoting velocity and the decreasing torque of high speed train. In the meantime, the meshing tooth number of gear pair is equal or more than two in the three conditions. Besides, combining the theory of mechanical principle and the relevant parameters in Table 1, the calculation value of G301 helical gear pair contact ratio is 2.45 (Sun et al., 2003). It states that traction helical gear of CRH380A high speed train has the large contact ratio which ensures the meshing transmission stability of traction helical gear in working process and verifies the reliability of simulation result at a certain degree.

In order to compare the different contact pressure maps of gear pair in the three conditions, the maximum contact pressures of helical gear pair in different meshing positions are extracted and listed in Table 3.

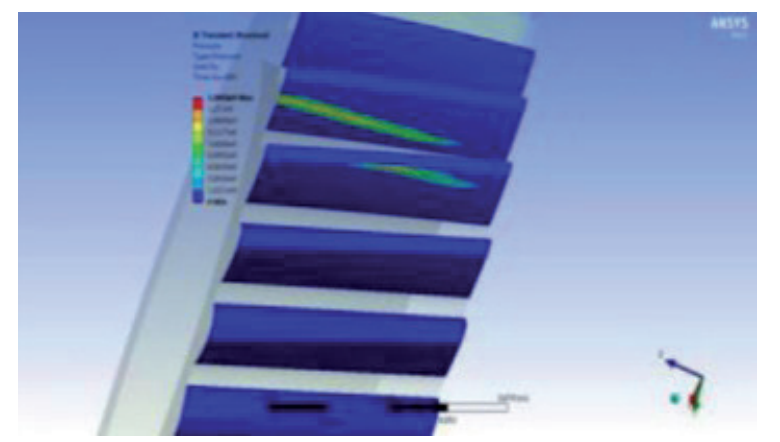

(a)

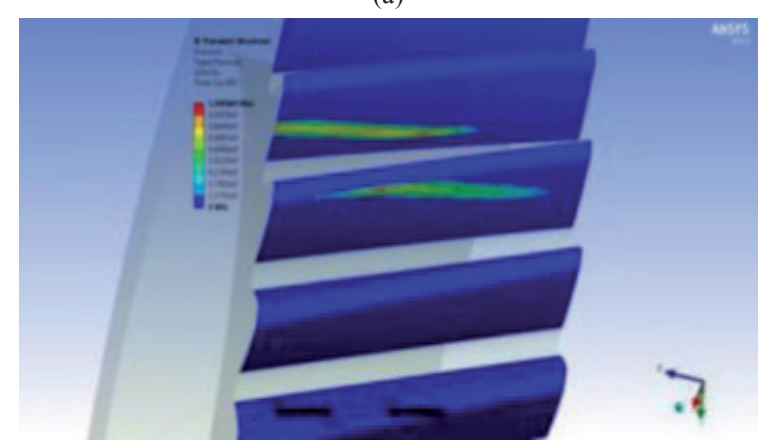

(c)

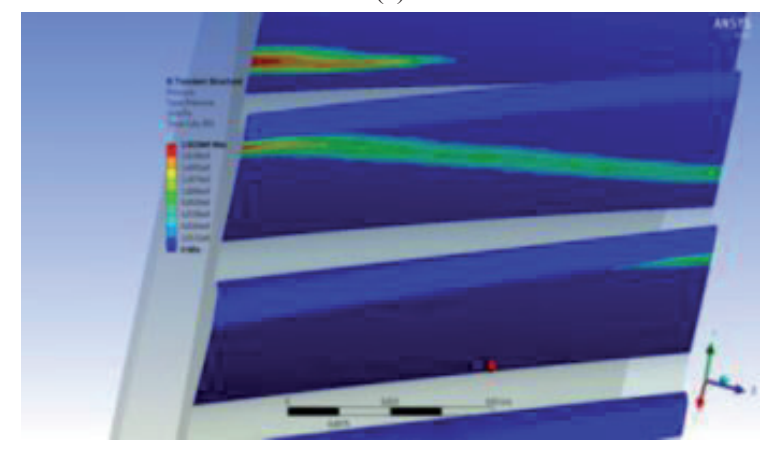

(e)
The followings can be got from Table 3, the maximum contact pressure in mesh in or out is larger than that of in normal meshing process. Meanwhile, compared with the mesh out process, the maximum contact pressure of helical gear in mesh in is much larger. This is because at the moment of mesh in and out among the transmission process of gear pair, the gear body stress is loaded and elastic deformation becomes large. And this leads to the mesh in and out points have a certain deviation with the theoretical meshing points, so the big meshing impact is generated and the helical gear contact pressure rises rapidly. Furthermore, the meshing impact effect of mesh in is much larger than mesh out. In the three conditions, all of the maximum contact pressures about helical gear pair occur in the mesh in process. And the meshing impacts exist in the three conditions. Simultaneously, the meshing impact of helical gear in high speed condition is the maximum one, the reason is that not only the contact pressure is a little large but also the temperature of gear body has a little increase when the gear is in fast revolving.

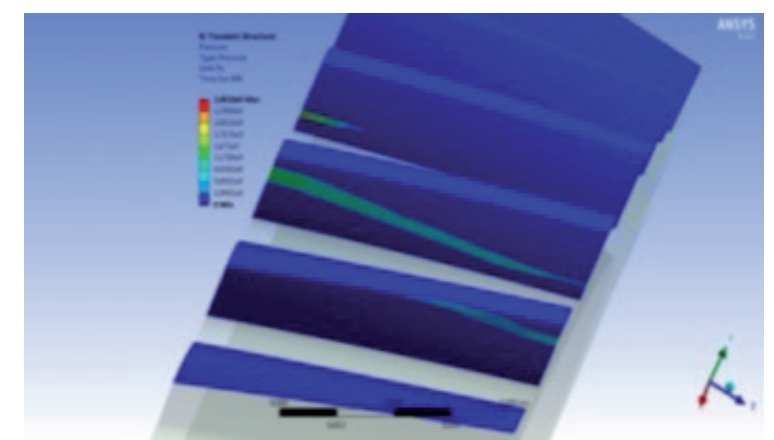

(b)

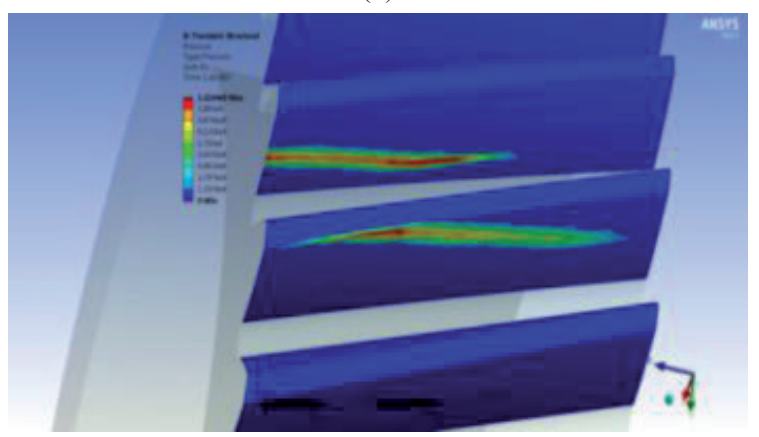

(d)

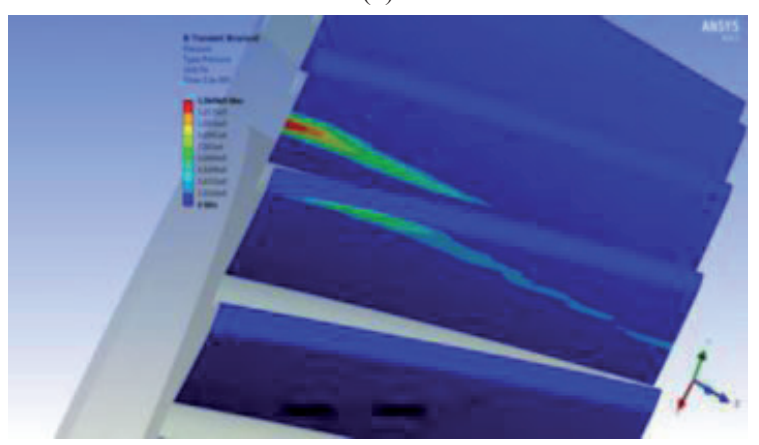

(f)

Fig. 5 Contact pressure maps of different meshing positions in start-up condition 


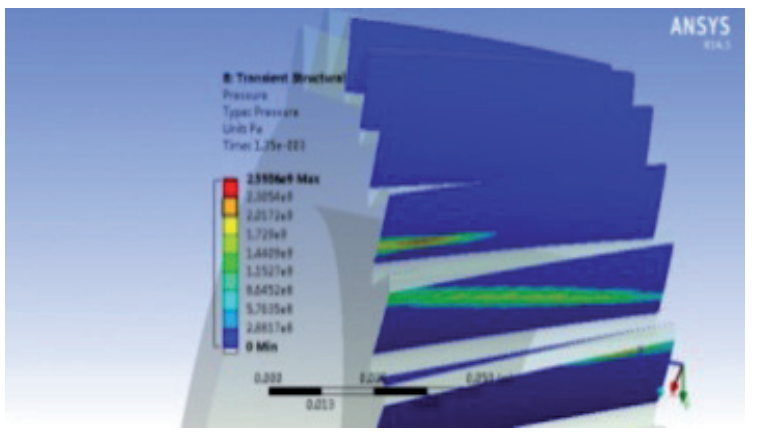

(a)

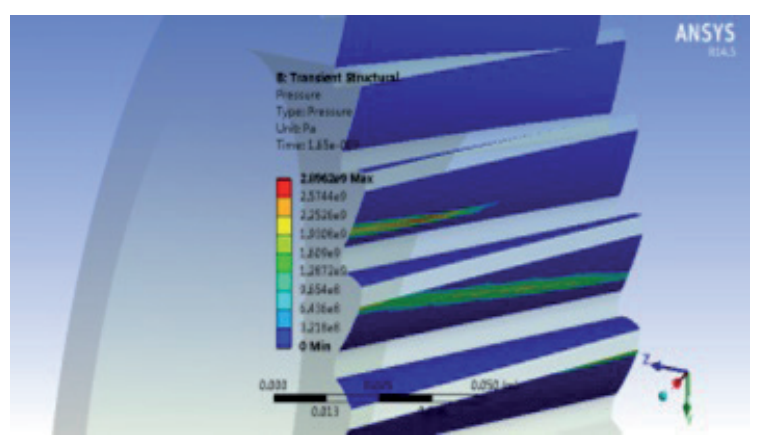

(c)

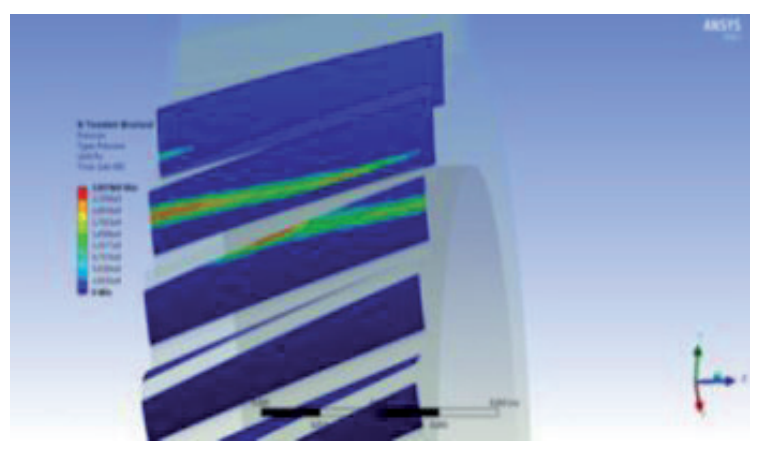

(e)

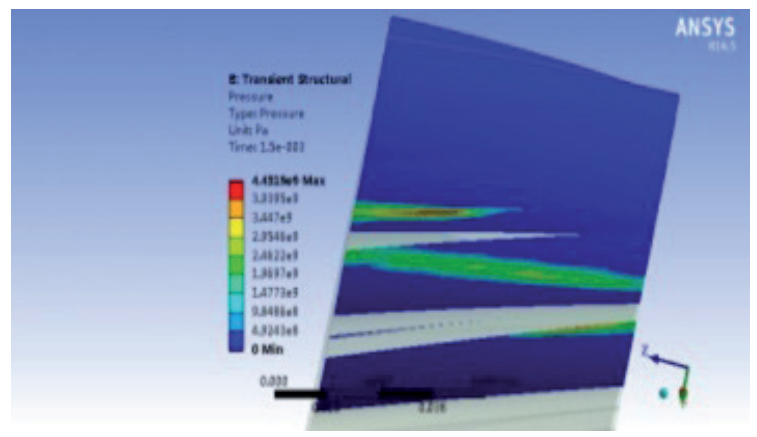

(b)

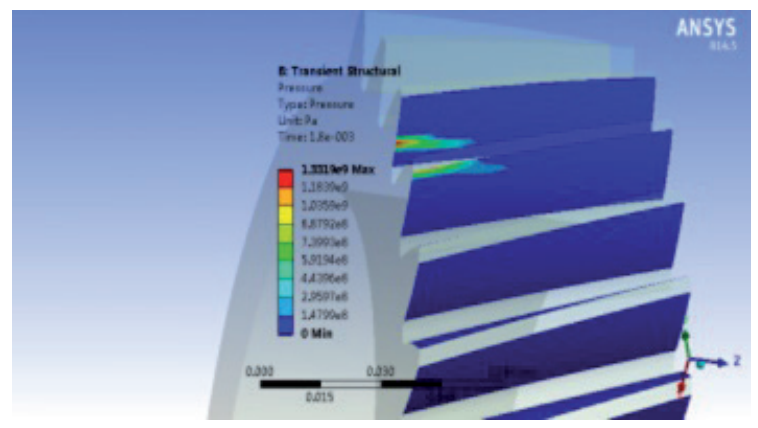

(d)

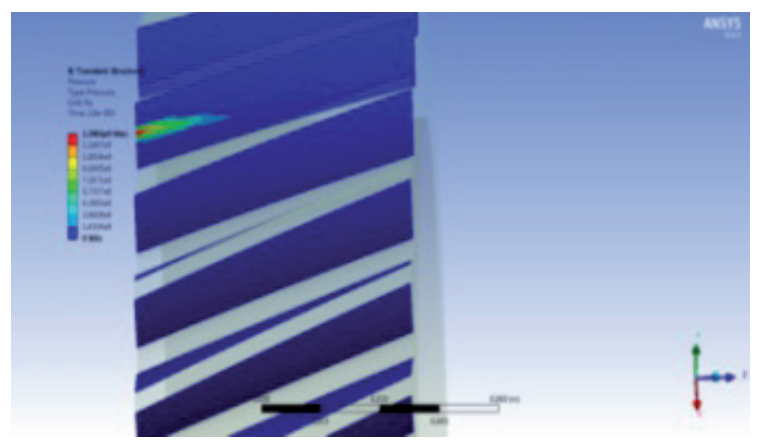

(f)

Fig. 6 Contact pressure maps of different meshing positions in continuous condition

Table 3 Maximum contact pressures at different meshing positions

\begin{tabular}{lllllll}
\hline Figure number & (a) & (b) & (c) & (d) & (e) & (f) \\
\hline Meshing position & Mesh & Mesh-in & Mesh & Mesh & Mesh-out & Mesh \\
Start-up (MPa) & 1369 & 2641 & 1240 & 1218 & 1811 & 1364 \\
Continuous (MPa) & 2247 & 3662 & 964.7 & 2146 & 2627 & 1290 \\
High speed (MPa) & 2593 & 4431 & 2896 & 1331 & 3325 & 1629 \\
\hline
\end{tabular}

\section{Conclusion}

This paper analyzed meshing characters and tractive performance curve about traction helical gear of China railway high speed train. And then, tookG301 traction helical gear of CRH380A high speed train for example, used Pro/E and ANSYS workbench software to analyze the dynamic contact stress state about the traction helical gear in the three conditions including start-up, continuous and high speed. The main conclusions obtained from this work can be summarized as below:
(1) In the meshing transmission process about traction helical gear of China railway high speed train, the gear toothhas a large contact ratio. The stress of traction helical gear increases with the increasing revolving speed in the three conditions.

(2) The maximum equivalent stress of the gear pair locates in contact area and diffuses to the gear body gradually. Meanwhile, the stress concentration also occurs in tooth root. 


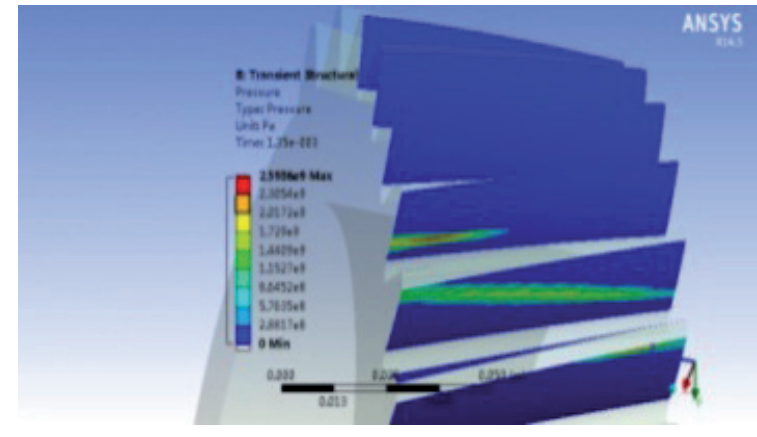

(a)

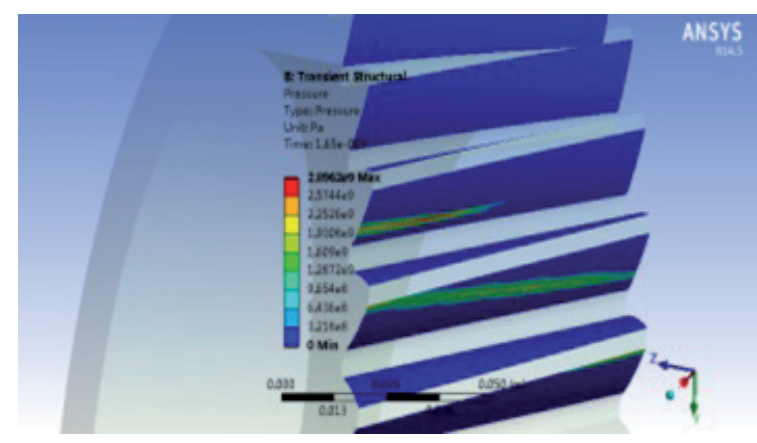

(c)

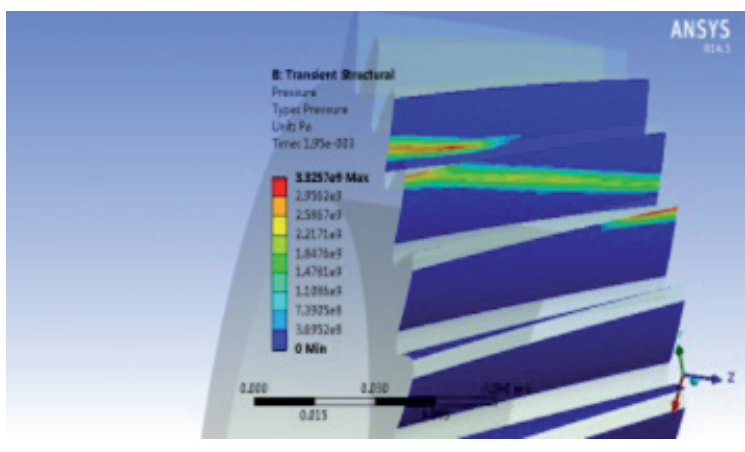

(e)

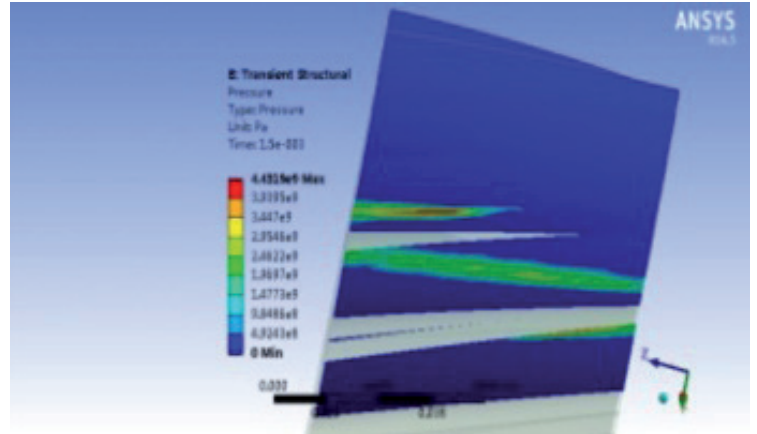

(b)

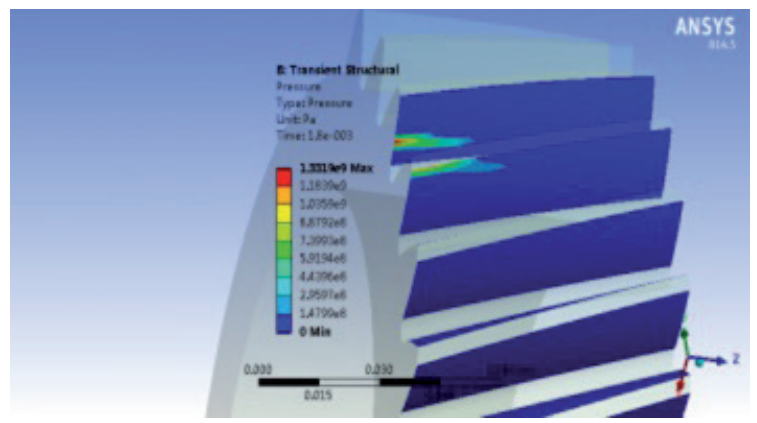

(d)

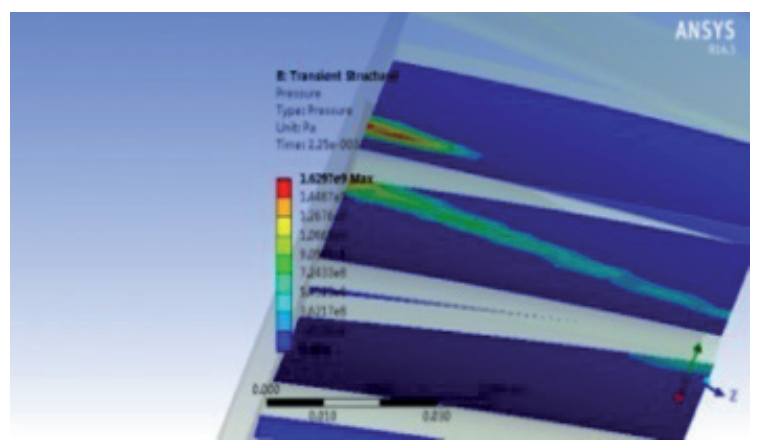

(f)

Fig. 7 Contact pressure maps of different meshing positions in high speed condition

(3) The location of the maximum contact pressure changes with the gear's transmission. There are some certain impacts when the gears are in mesh in and out processes. In addition, the mesh in process has the larger impact compared with mesh out process.

(4) Using finite element method can obtain working status information about each parts of gear pair. It provides some certain references and foundations to structure design and modification, strength analysis and life design.

\section{Acknowledgements}

This work was sponsored by the Jiangxi Province Foreign Cooperation in Science and Technology(20151BDH80011), and it was also funded by the Jiangxi Province 2014 Voyage Engineering Project.

\section{References}

Gašparík, J., Abramović, B., Halás, M. (2015) New Graphical Approach to Railway Infrastructure Capacity Analysis. PROMET - Traffic and Transportation. 27(4), pp. 283-290. DOI: 10.7307/ptt.v27i4.1701

Chen, Y., Liu, C. (2011) Contact stress analysis of concave conical involute gear pairs with non-parallel axes. Finite Elements in Analysis and Design. 47, pp. 443-452. DOI: 10.1016/j.finel.2010.12.005

Conrado, E., Gorla, C. (2011) Contact fatigue limits of gears, railway wheels and rails determined by means of multiaxial fatigue criteria. Procedia Engineering. 10, pp. 965-970. DOI: 10.1016/j.proeng.2011.04.159

Fan, Z., Zhao, X., Zuo, H. (2010) The Contact Finite Element Analysis of Helical Gear based on ANSYS. Journal of Mechanical Transmission. 4, pp. 68-70.

Fedorko, G., Molnár, V., Michalik, P., Dovica, M., Tóth, T., Kelemenová, T. (2016) Extension of inner structures of textile rubber conveyor belt-Failure analysis. Engineering Failure Analysis. 70, pp. 22-30. DOI: $10.1016 /$ j.engfailanal.2016.07.006

Higher speed experiment train. (2015) [Online]. Available from: http://baike. baidu.com/view/7166230.htm [Accessed: 18th November 2015] 
Hu, Y.-M., Shao, Y., Chen, Z. G., Zuo, M. J. (2011) Transient meshing performance of gears with different modification coefficients and helical angles using explicit dynamic FEA. Mechanical Systems and Signal Processing. 25(5), pp. 1786-1802. DOI: 10.1016/j.ymssp.2010.12.004

Ivanco, V., Kmet, S., Fedorko, G. (2016) Finite element simulation of creep of spiral strands. Engineering Structures. 117, pp. 220-238.

DOI: 10.1016/j.engstruct.2016.02.053

Jabbour, T., Asmar, G. (2015) Tooth stress calculation of metal spur and helical gears. Mechanism and Machine Theory. 92, pp. 375-390. DOI: 10.1016/j.mechmachtheory.2015.06.003

Patil, S., Karuppanan, S., Atanasovska, I. (2016) Experimental measurement of strain and stress state at the contacting helical gear pairs. Measurement. 82, pp. 313-322. DOI: 10.1016/j.measurement.2015.12.046

Sun, H., Chen, Z. (2003) Theory of machines. Higher Education Press, Beijing.
Tong, C., Sun, Z.-L., Ma, X.-Y., Cha, X.-D. (2014) Dynamic simulation of spur gears with assembly errors and machining errors. Journal of Northeastern University(Natural Science). 35(7), pp. 996-1000. DOI: 10.3969/j.issn.1005-3026.2014.07.019

Wan, Z., Cao, H., Zi, Y., He, W., Chen, Y. (2015) Mesh stiffness calculation using an accumulated integral potential energy method and dynamic analysis of helical gears. Mechanism and Machine Theory. 92, pp. 447-463. DOI: 10.1016/j.mechmachtheory.2015.06.011

Wang, W., Meng, M., Cha, L., Cao, Z. (2013) Domestication study of high speed train traction gear. Locomotive \& Rolling Stock Technology. 2, pp. 9-10.

Zong, L., Li, X., Ma, W., Liu, W. (2014) Analysis of Drivetrain Modeling and Dynamic for EMU. Machinery Design \& Manufacture. 9, pp. 95-98. 